\title{
BMJ Open Realist evaluation of intersectoral oral health promotion interventions for schoolchildren living in rural Andean communities: a research protocol
}

\author{
Dave A Bergeron, ${ }^{1,2}$ Lise R Talbot, ${ }^{3}$ Isabelle Gaboury ${ }^{4}$
}

To cite: Bergeron DA, Talbot LR, Gaboury I. Realist evaluation of intersectoral oral health promotion interventions for schoolchildren living in rural Andean communities: a research protocol. BMJ Open 2017;7:e014531.

doi:10.1136/bmjopen-2016014531

- Prepublication history for this paper is available online. To view these files please visit the journal online (http://dx.doi.org/10.1136/ bmjopen-2016-014531).

Received 29 September 2016 Revised 20 December 2016 Accepted 25 January 2017

CrossMark

For numbered affiliations see end of article.

\section{Correspondence to}

Professor Isabelle Gaboury; isabelle.gaboury@

usherbrooke.ca

\section{ABSTRACT}

Background: Intersectoral collaboration, known to promote more sustainable change within communities, will be examined in an oral health promotion program (OHPP). In Peru, an OHPP was implemented by the Ministry of Health, to reduce the incidence of caries in schoolchildren. In rural Andean communities, however, these initiatives achieved limited success. The objectives of this project are: (1) to understand the context and the underlying mechanisms associated with Peruvian OHPP's current effects among school children living in rural Andean communities and (2) to validate a theory explaining how and under which circumstances OHP intersectoral interventions on schoolchildren living in rural Andean communities produce their effects.

Methods and analysis: Through a realist evaluation, the context, underlying mechanisms and programme outcomes will be identified. This process will involve five different steps. In the first and second steps, a logic model and an initial theory are developed. In the third step, data collection will permit measurement of the OHHP's outcomes with quantitative data, and exploration of the elements of context and the mechanisms with qualitative data. In the fourth and fifth steps, iterative data analysis and a validation process will allow the identification of ContextMechanism-Outcome configuration, and validate or refine the initial theory.

Ethics and dissemination: This research project has received approval from the Comité d'éthique de la recherche en santé chez l'humain du Centre hospitalier universitaire de Sherbrooke. The initial theory and research results will be published in relevant journals in public health and oral health. They will also be presented at realist evaluation and health promotion international conferences.

\section{INTRODUCTION}

Oral health $(\mathrm{OH})$ is an essential health component ${ }^{1-3}$ as it is linked to well-being and quality of life. ${ }^{2}$ Of all oral diseases, dental caries are the most important $\mathrm{OH}$ problem worldwide. ${ }^{1}$ Dental caries represent the third

\section{Strengths and limitation of this study}

- A realist evaluation is especially useful to explore and understand the influences of context and underlying mechanisms on intervention effects in complex situations such as deployment of intersectoral collaboration.

- This study will underpin the development of an emerging theory regarding the implementation of intersectoral collaboration in health promotion programmes, including oral health promotion.

- Language and cultural barriers will be present throughout the research project and may influence data collection and the process of analysis.

global disease plague, ${ }^{5}$ and prevalence is increasing among schoolchildren in developing countries, ${ }^{6} 7$ particularly in Latin America. ${ }^{6-8}$ This problem affects primarily children of the poorest and marginalised populations. $^{7}$ Furthermore, dental caries could be considered a complex problem because many factors (individual, familial, social and environmental) contribute to its development. $^{79}{ }^{10}$ The children experience multiple consequences, ${ }^{7} 9^{11-13}$ as do their parents $^{1}{ }^{11-15}$ and the local health system..$^{11-14}$ Considering the complexity of the problem of dental caries, and major impacts at different levels, this is a major public health problem. ${ }^{16}$ Since the prevalence of dental caries is increasing in developing countries, a resolution was adopted by WHO to target $\mathrm{OH}$ problems in developing countries. ${ }^{17}$ To tackle a complex problem such as dental caries, it is necessary to develop intersectoral actions. ${ }^{13}$

In Peru, as in other developing countries, dental caries are a concern among schoolchildren, particularly in rural Andean communities. ${ }^{18}$ Despite mixed evidence, ${ }^{19-21}$ several authors indicate that an oral health promotion program (OHPP) with schoolchildren can counter this problem. ${ }^{4} \quad 19 \quad 20$ 
To ensure effective, optimal and sustainable change, OHPP should be implemented in collaboration with different local stakeholders (including parents) ${ }^{13} 1920$ 22-24 and grounded on theoretical basis. ${ }^{19}{ }^{20}$ To adapt Peruvian OHPP to the realities of rural Andean communities, it is important to understand how OHPP works in depth ${ }^{19}$ for those communities including the different elements influencing the development of collaboration between local stakeholders involved ${ }^{25}$ in OHPP.

\section{OHPP interventions}

To reduce dental caries impacts, it is necessary to invest in oral health promotion (OHP) interventions. ${ }^{1}{ }^{3}$ Individual $\mathrm{OH}$ education programmes may improve $\mathrm{OH},{ }^{2}$ but without further actions engaging different stakeholders, effects of programmes are barely significant or not sustainable in the long term. ${ }^{12} 2627$ An OHPP programme with a comprehensive approach including stakeholders' participation could have a long-term effect. $^{12}{ }^{22}$ Health promotion programmes (including OHPP) can be defined as collective actions to produce change, that is, deemed to be desirable in a population. ${ }^{28}$ For OHPP targeting schoolchildren, school is an appropriate environment to conduct OHP interventions, ${ }^{22} 29$ since children are usually more receptive and it also facilitates access to community members-the families and teachers. ${ }^{22}$

The Peruvian OHPP was developed by the Ministry of Health in $2007^{30}$ and was improved up to 2013 when health promotion interventions (including OHP) were implemented in primary schools. ${ }^{31}$ On an annual basis, $\mathrm{OH}$ professionals perform four types of OHP activities in schools: (1) training on oral hygiene and eating habits related to $\mathrm{OH}$; (2) tooth brushing and flossing demonstrations; (3) distribution of toothbrushes and fluoride toothpaste and (4) application of fluoride or sealants on children's teeth. OH professionals working in public health centres must achieve goals related to those $\mathrm{OH}$ activities. Usually, teachers are also involved in OHP. They perform daily promotion of tooth brushing at school and ensure that children have a toothbrush and fluoride toothpaste available at school. ${ }^{31-34}$

Insufficient cooperation with local stakeholders during the implementation process has been shown to explain poor performance of several health promotion programmes. ${ }^{23} 35$ Therefore, intersectoral collaboration is necessary $^{12} 22-26 \quad 35-37$ to optimise the effectiveness and efficiency of programmes, and to ensure their sustainability. ${ }^{23} 243538$

Intersectoral collaboration is defined as a collective action where several stakeholders with a common goal take on different roles. ${ }^{23}$ This process facilitates networking and the sharing of information, resources, activities and capabilities among different involved stakeholders. ${ }^{39}$ Unfortunately, intersectoral collaboration is not always present in the implementation process of health promotion programmes. ${ }^{23} 35$
Currently in Peru, OHPP is a responsibility of dentists working in health centres. In the face of a shortage of dentists and low involvement in $\mathrm{OH}$ by other health professionals, ${ }^{40}$ current deployment of OHPPs is rather uneven in the different regions of the country. ${ }^{41}$ In some places, non-governmental organisations are working with health authorities to ensure programme deployment. ${ }^{42}$ Indeed, it is not possible to know the extent of collaboration with different stakeholders with the Peruvian OHPP.

In some parts of Peru, OHP interventions show promising results such as increased tooth brushing by children. ${ }^{42-44}$ Favourable outcomes, however, emerge slowly in some Andean regions. ${ }^{45}$ Why are the current dental caries prevention activities conducted among schoolchildren not resulting in improved behaviours and $\mathrm{OH}$ ? How is collaboration with stakeholders and organisations being deployed, or perhaps thwarted? Can collaboration between stakeholders and organisations optimise dental caries prevention? Very few models and theories have been developed in conjunction with community OHP and intersectoral collaboration. ${ }^{46}$ To adapt the Peruvian OHPP adequately to local circumstances, and to optimise collaboration with different stakeholders in rural communities, it is crucial to understand elements of context and underlying mechanisms ${ }^{47}$ that may explain the continuing high prevalence and incidence of dental caries among schoolchildren in rural Andean communities.

\section{METHODS AND ANALYSIS Objectives}

The objectives of this research are: (1) to understand the context and the underlying mechanisms associated with Peruvian OHPP's current effects among schoolchildren living in rural Andean communities and (2) to validate a theory explaining how and under which circumstances OHP intersectoral interventions on schoolchildren living in rural Andean communities produce their effects.

\section{Study design}

In order to understand better the factors influencing OHPP implementation, it is essential to consider local stakeholders' and various professionals' views on the programme, and to foster their active participation in the evaluation process. ${ }^{46}$ A realist evaluation will include different types of participants, in order to achieve the research objectives. This research methodology has been developed from a postpositivist perspective to explore and understand influence of context and underlying mechanisms on intervention effects. ${ }^{47-52}$ This design is often used to assess complex situations such as deployment of intersectoral collaboration ${ }^{53}$ as it facilitates the connection of different elements that may influence interventions' effectiveness in specific environments. ${ }^{54}$ 
In realist evaluation, the context, underlying mechanisms and programme outcomes are delineated and inter-relations are explored. The context includes pre-existing elements of the environment where interventions occur. ${ }^{48} 505556$ Underlying mechanisms are elements of stakeholders' reasoning and reactions, depending on the context and resources deployed when interventions are performed. ${ }^{57}$ Frequently multiple mechanisms can explain interventions' outcomes, ${ }^{50} 5556$ but they may be obscured and difficult to identify. ${ }^{52}$ According to realist evaluation, interventions' outcomes are the result of multiple causes and depend on mobilised mechanisms and elements of the context where interventions are performed. ${ }^{48}{ }^{50}{ }_{58}$ Finally, Context-Mechanism-Outcome (CMO) chains are a conceptual tool that connects elements of context, mechanisms and intervention outcomes. ${ }^{48} 50$

This research design encourages complementary use of qualitative and quantitative methods in order to understand a range of phenomena that can explain programme outcomes. Quantitative methods will document intervention outcomes descriptively and allow stakeholders to explore, by inference, the mechanisms involved ${ }^{59}{ }^{60}$ Elements of context and mechanisms will be explored with stakeholders using qualitative methods such as semistructured interviews and focus groups. ${ }^{51} 59-61$

Realist evaluation is usually divided into four distinct steps; however, in this study we have added an additional step: the development of a programme logic model. This addition helps to explain further the programme implementation process and to understand better the mobilised resources and activities carried out. ${ }^{58}$ Thus, the five steps are as follows: (1) development of a logic model; (2) development of an initial theory; (3) data collection; (4) data analysis, to highlight regularities and relationships between elements of context, mechanisms and outcomes, and to develop CMO chains and (5) initial theory validation and refinement. This process, used iteratively, will generate a final theory explaining the programme CMO configurations. ${ }^{49-515661}$

\section{First step: development of a logic model}

We conducted a review of various policies on OHP with schoolchildren, adopted by the Peruvian government between 2007 and 2013. Following this review, we developed a logic model for Peruvian OHPP directed at schoolchildren (table 1).

\section{Second step: development of initial theory}

To explore the actual effects of the Peruvian OHPP, we elaborated an initial theory. This process was carried out following a literature review on the deployment of community health promotion programmes; intersectoral collaboration during the implementation process of health promotion programmes and contextual elements and underlying mechanisms explaining such programme outcomes. Considering the importance of social, physical and environmental factors on $\mathrm{OH}^{10}{ }^{162}$ this initial theory is based on an ecological approach, ${ }^{63}$ and combines OHPP components, stakeholders involved and OHPP's expected effects on schoolchildren. Following the literature review, four probable elements of context and 12 probable mechanisms that may explain OHPP's effects were included in the initial theory. Two types of mechanisms could explain OHHP's effects. First, situational mechanisms would help to develop intersectoral collaboration between stakeholders involved and thus foster their joint and individual involvement. Second, transformational mechanisms would explain every stakeholder contribution to OHPP's effects. ${ }^{64}$ A director of the Regional Health Authority as well as a director of a non-governmental organisation working in targeted rural communities validated this process. This initial theory will be published separately.

\section{Third step: data collection}

\section{Setting}

To validate the initial theory, three rural communities in Cusco region were selected. These communities were selected because all stakeholders included in the initial theory are represented; and OHPP interventions have been conducted there previously. Before data collection, there will be a meeting with community stakeholders to confirm their interest in participating in the research project.

\section{Participants}

Two types of participants will be enrolled in this study: (1) children attending primary school, to measure OHPP's effects; and (2) various stakeholders (health workers, teachers, parents and other community stakeholders) present in rural communities, to explore and validate different underlying mechanisms that may explain OHPP's effects.

A meeting with the members of each community being studied will be organised to introduce the research project. At the end of this meeting, parents who want their children to participate in the research project will be invited to meet one of the research team members, who will present the consent form for their children. Other stakeholders targeted for this study will be contacted after the meeting to gather their consent to participate. Consent forms for stakeholders and children's parents are available in Quechua and Spanish.

Children will be recruited with a census in the selected communities of all children whose parents have given their consent. Children from 9 to 13 years old will be chosen because the majority of permanent teeth (except third molars) are present at this age, which facilitates international comparisons and epidemiological surveillance. ${ }^{65}$ The tools used in this study were validated with children of similar age to those who will participate in this research. ${ }^{66}{ }^{67}$ According to school lists in the three communities, the potential child population $9-13$ years of age is $\sim 80$ children. 
Table 1 Logic model for Peruvian OHPP directed at schoolchildren

\begin{tabular}{|c|c|}
\hline Program target & Schoolchildren (including preschoolers) \\
\hline Program context & $\begin{array}{l}\text { Program developed by the Ministry of Health in } 2007 \text {. Development of a collaboration } \\
\text { agreement with the Ministry of Education in } 2008 \text { and with the Peruvian College of } \\
\text { Dentists in } 2009 \text {. Improvement of the programme in } 2012 \text { by the Ministry of Health and } \\
\text { in } 2013 \text { by the President of the Republic, which requires the implementation of health } \\
\text { promotion interventions (including oral health) in all primary schools (including } \\
\text { preschool) in Peru }\end{array}$ \\
\hline Levels of intervention & $\begin{array}{l}\text { 1. Schoolchildren (individual level), } \\
\text { 2. Parents (interpersonal level), } \\
\text { 3. Schools (organisational level), } \\
\text { 4. Rural communities (community level) }\end{array}$ \\
\hline Objective & $\begin{array}{l}\text { Decreased oral health problems for schoolchildren to improve chewing ability, } \\
\text { self-esteem and quality of life } \\
\nabla\end{array}$ \\
\hline $\begin{array}{l}\text { Components } \\
\text { carried out in schools }\end{array}$ & $\begin{array}{l}\text { 1. Promotion of daily tooth brushing with fluoride toothpaste in schools } \\
\text { 2. Education session and demonstration on oral health in schools } \\
\text { 3. Application of sealant or fluorine (varnish or gel) } \\
\text { 4. Involvement of parents and community authorities } \\
\text { v }\end{array}$ \\
\hline Resources & $\begin{array}{l}\text { 1. Health centre dentists } \\
\text { 2. Preschool and primary school teachers } \\
\text { 3. Oral health promotion materials distributed by the Ministry of Health } \\
\text { (poster, presentation, toothbrush, fluoridated toothpaste, dental products) }\end{array}$ \\
\hline Output & $\begin{array}{l}\text { 1. Application of fluorine (gel or varnish) or sealant } \\
\text { 2. Education session with children two or three times per year } \\
\text { 3. Daily tooth brushing with fluoridated toothpaste in schools } \\
\text { v }\end{array}$ \\
\hline $\begin{array}{l}\text { Short-term outcomes (knowledge } \\
\text { and attitudes) }\end{array}$ & $\begin{array}{l}\text { 1. Increased knowledge on oral health among schoolchildren } \\
\text { 2. Increased positive attitudes toward oral health among schoolchildren } \\
\text {. }\end{array}$ \\
\hline $\begin{array}{l}\text { Medium-term outcomes } \\
\text { (behaviours) }\end{array}$ & $\begin{array}{l}\text { 1. Increased daily tooth brushing with fluoridated toothpaste among schoolchildren } \\
\text { 2. Increased oral hygiene among schoolchildren } \\
\text { v }\end{array}$ \\
\hline Long-term outcomes (Conditions) & $\begin{array}{l}\text { 1. Decreased dental plaque among schoolchildren } \\
\text { 2. Decreased dental caries among schoolchildren } \\
\text { 3. Increased quality of life related with oral health among schoolchildren }\end{array}$ \\
\hline
\end{tabular}

OHPP, oral health promotion program.

Before data collection with children, a member of the research team will introduce them to the research project and will obtain the child's assent to participate. Child assent will be recorded along with the child's parental signed consent form.

Stakeholders will be recruited according to a theoretical sampling ${ }^{68}$ so that all categories of stakeholders identified in the initial theory are represented: (1) health workers; (2) teachers; (3) parents and (4) other community stakeholders (members of municipal assemblies, members of school parent associations, local health promoters). ${ }^{51} 69$ They will be identified and approached by research team members. To validate the elements of context and the mechanisms, a minimum of two participants per community will be recruited for each category of stakeholders.

All participants must meet the following inclusion criteria: (1) speak Spanish or Quechua and (2) live or work within the selected communities. The exclusion criterion for this research project is the presence of any disease, or cognitive or sensory deficit limiting social interactions.

\section{Data collection process}

The data collection process will validate and enhance elements of context, mechanisms and outcomes described in the initial theory, summarised in table 2. A research team will assist with data collection. Research team members were chosen for their knowledge of the environment in which the study is being carried out and their fluency in Quechua and Spanish. Before data collection, objectives, logistics, techniques and instruments to collect quantitative and qualitative data will be reviewed by the research team ${ }^{70} 71$ to ensure inter-rater reliability and internal validity of the quantitative scales. Examiners will be calibrated, and will proceed to data collection when a Kappa score of at least 0.8 has been reached. ${ }^{65}$ 
Table 2 Data collection process to measure OHPP outcomes, elements of context and mechanisms

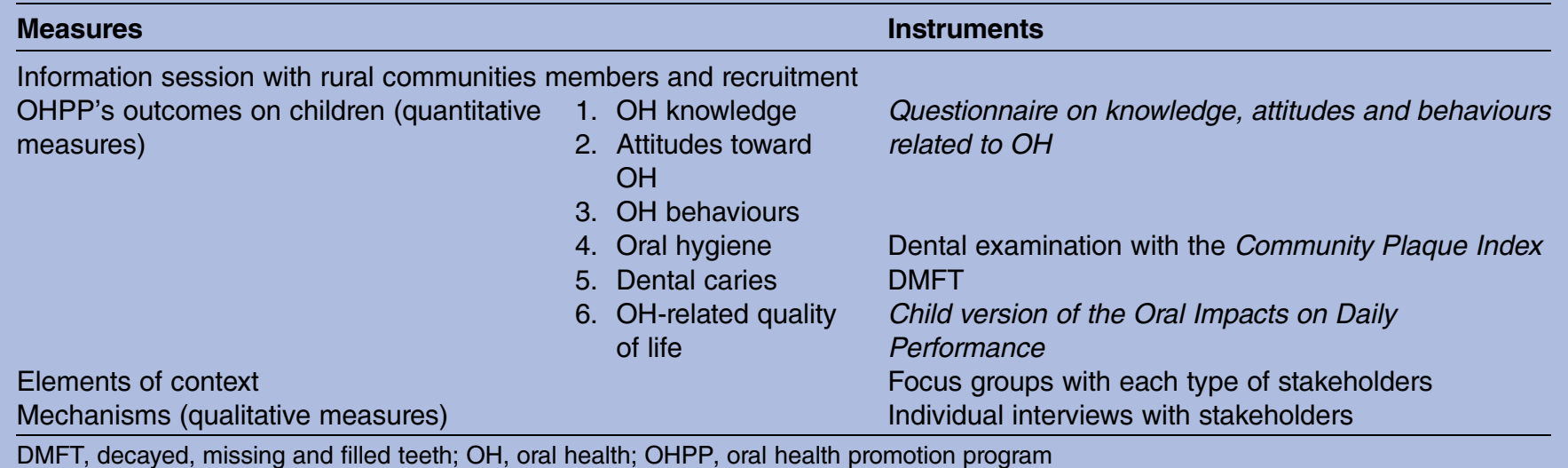

\section{Measures of OHPP's outcomes}

Measurement of the OHPP's outcomes will be carried out with child participants, using tools and questionnaires presented in table 1 . A pretest of all these instruments will be made with a group of children having similar characteristics, but not participating in the research project.

To measure $\mathrm{OH}$ knowledge, attitudes and behaviours, the Questionnaire on knowledge, attitudes and behaviours related to $\mathrm{OH}$ developed and validated by Poutanen $\mathrm{Lahti}^{66}$ was selected following a review of different questionnaires. Using Likert scales to measure children's knowledges, attitudes and behaviours, this self-administered questionnaire was used in several studies including studies selected to develop the present initial theory. ${ }^{72}$ An initial version of this questionnaire was validated with 53 children. Cronbach's alphas were 0.70 for knowledge, 0.75 for attitudes and 0.85 for behaviours related to $\mathrm{OH}$. The clinical presence of plaque and gingivitis has been found to correlate with low self-reported $\mathrm{OH}$ behaviours in children who have completed the questionnaire. ${ }^{73}$

For this research, the Questionnaire on knowledge, attitudes and behaviours related to $\mathrm{OH}$ was translated from English to Spanish following a reverse parallel translation process. ${ }^{74}$ In order to use it with participants whose native language is Quechua, the questionnaire was translated from Spanish into Quechua by an anthropologist speaking Spanish and Quechua. Later, Spanish and Quechua versions of the questionnaire were adapted and validated. The adapted version use in this study includes 26 items on behaviour, 14 items on attitudes and four items on knowledge related to $\mathrm{OH}$. The translation, adaptation and validation process in Spanish of the Questionnaire on knowledge, attitudes and behaviours related to $\mathrm{OH}$ will be published subsequently.

To measure the presence of dental cavities and the level of $\mathrm{OH}$, dental examinations will be conducted by $\mathrm{OH}$ professionals, according to the WHO recommendations. To ensure standardisation of dental examinations, a pretest will be done to measure interjudge reliability. The presence of dental caries will be reported using the decayed, missing and filled teeth (DMFT) index. ${ }^{65}$
The presence of dental plaque, a good indicator of a child's oral hygiene, ${ }^{75}{ }^{76}$ will be measured using the Community Plaque Index. This index was developed by Corchuelo $^{75}$ to simplify oral hygiene evaluation, and was validated with 83 children. Following the validation process, the index was found to be strongly correlated with the O'Leary index (sensitivity of 96.3 and specificity of 75.0), which is recognised as the gold standard to measure oral hygiene and dental plaque. ${ }^{75}$

The Peruvian Spanish version of Child Oral Impacts on Daily Performance (Child-OIDP) will be used to measure children's OH-related quality of life. This questionnaire was developed by Gherunpong $e t a l^{77}$ and has been translated into Spanish following a reverse parallel translation process and adapted for Peru by Bernabé, et $a l^{67}$ Child-OIDP assesses the $\mathrm{OH}$ impact in connection with eight daily activities of children. For each activity, the questionnaire assesses the presence of an impact, its frequency and its severity. The process of validation of the Peruvian Spanish version of the Child-OIDP took place with 865 children aged 11-12 years old. Cronbach's $\alpha$ for internal consistency is 0.62 , and testretest reliability with an intraclass correlation coefficient is $0.85 .{ }^{67}$ In order to use this questionnaire with children whose native language is Quechua, the Peruvian Spanish version of Child-OIDP was translated from Spanish into Quechua by an anthropologist speaking Spanish and Quechua and validated qualitatively with two community workers and four children speaking Quechua.

\section{Measures of elements of context and mechanisms}

To identify and confirm different elements of context and mechanisms that may explain OHPP's effects, focus groups will be conducted in Spanish or Quechua with an open interview grid $^{71}$ developed using the initial theory and in accordance with the principles of the realist interview. ${ }^{78}$ During the data collection process, the interview grid will be augmented to incorporate emerging themes. ${ }^{68}$ To ensure group homogeneity, ${ }^{70}$ focus groups will be conducted with each of the types of actors from both communities targeted, for a total of four focus group discussions. Groups will have a 
maximum of eight participants, to facilitate interactions among participants. ${ }^{70}$

To further explore and validate various themes that emerge during focus groups, semistructured interviews will be conducted with a minimum of two persons per stakeholder types (a minimum of eight interviews). The interview grid developed with the initial theory and in accordance with the principles of realist interview ${ }^{78}$ will be enhanced if additional themes emerge. ${ }^{68}$ Interviews will be conducted by a member of the research team speaking Quechua and Spanish. Focus groups and interviews will be recorded ${ }^{71}$ and transcribed verbatim ${ }^{68}$ in Spanish by the research team. Coanalysis will be performed from the Spanish version. ${ }^{79}$

\section{Fourth and fifth steps: data analysis and theory refinement} Quantitative analysis of OHPP effects

Continuous variables will be analysed for each community using descriptive statistics, including frequency tables, central tendency and dispersion measures. The effects of the OHPP will be summarised for stakeholders at the beginning of each focus group. This process will thus allow stakeholders to explore by inference, mechanisms that may explain these effects. ${ }^{59} 60$

\section{Qualitative analysis}

Qualitative data collection and analysis will be done iteratively and non-linearly. ${ }^{80}$ Content analysis will permit the identification of emerging and recurring themes from the data. A semistructured analysis grid developed with the initial theory and realist evaluation core concepts will allow causal data coding from a confirmatory perspective. ${ }^{78}$ This process will facilitate identification of elements of context and mechanisms influencing the OHPP's effects. ${ }^{68}$ NVivo 11 will be used to code qualitative data. This software allows coanalysis and integration of quantitative data, to facilitate pattern identification. $^{81}$

Coanalysis of the results will entail independent analyses of transcripts, and differences of opinion will be discussed and validated by the team. Data interpretation will be supported by verbatim transcripts. ${ }^{68}$ The principal investigator will record events and thoughts in a diary throughout the data collection process. ${ }^{68} 82$ This will reduce subjectivity and improve credibility of the qualitative results. ${ }^{68}$

The variety of sources, methods, data types and researchers will allow data triangulation. ${ }^{68} 70$ Detailed descriptions of elements of context and the participation of different types of stakeholders involved in programme deployment will highlight different perspectives and rival explanations. ${ }^{69}$ These procedures will ensure credibility and transferability. ${ }^{68}$

\section{Integration of qualitative and quantitative data}

Qualitative and quantitative data will be integrated in two stages. Interpretation of the data from each community $^{80}$ will highlight CMO configurations, then, an intercommunity analysis will compare those different CMO configurations. This second analysis will foster the development of transferable explanations ${ }^{68}$ and will be used to refine and modify the initial theory. ${ }^{50} 515661$

The final theory will be validated with local stakeholders using two focus groups. ${ }^{51}$ One group will consist of health professionals and primary school teachers. The second group will include parents and other community stakeholders. This approach will ensure that community members can express themselves freely during the validation process.

\section{ETHICS AND DISSEMINATION}

For this study, formal consent will be obtained. Research data will be rendered anonymous, analysed in pooled groups rather than at the individual level, and communities will not be identified. Thus, identities of communities and project participants will remain confidential.

\section{Dissemination}

This research project is the first in $\mathrm{OH}$ to use such a research design. It is also one of the first studies in $\mathrm{OH}$ focusing on development of intersectoral collaboration in the process of implementation of OHP interventions. The main strengths of this research project are the use of multiple cases, mixed methods, validated quantitative tools $^{61}$ and realist interviewing principles. ${ }^{78}$

An important limitation is the presence of language and cultural barriers that will be present throughout the research project. $^{83}$ The presence of a local research team and adaptation of tools by an anthropologist working with those populations should decrease the effects of those barriers. Social desirability and elite bias could also be present, potentially affecting the credibility of the results. ${ }^{68}{ }^{84}$ Triangulation of sources and methods, multiple cases, exploration of rival explanations and final theory validation with two different groups of stakeholders should reduce those biases. ${ }^{68}$

The benefits from this research project could be numerous. From a research perspective, this study will allow the development of an emerging theory about the implementation of intersectoral health promotion programmes, including OHP. This study will allow, moreover, the translation and validation of questionnaires in Spanish and Quechua, which can be used for subsequent studies. For clinical practice, this research will provide recommendations to improve OHP interventions and will propose strategies focusing on intersectoral collaboration. These results could also be transferable to other contexts, particularly for disadvantaged or rural populations. For local people, this study will foster the deployment of OHP interventions in rural communities. This project may also provide a better understanding of specific elements of context in rural communities of developing countries, and may help to identify different mechanisms promoting adoption of healthy behaviour by people living in those communities. 
Author affiliations

${ }^{1}$ Department of Health Research Programs, Faculty of Medicine and Health Sciences, Université de Sherbrooke, Longueuil, Québec, Canada ${ }^{2}$ Department of Nursing, Université du Québec à Rimouski, Rimouski, Québec, Canada

${ }^{3}$ School of Nursing, Université de Sherbrooke, Sherbrooke, Québec, Canada

${ }^{4}$ Department of Family Medicine and Emergency Medicine, Faculty of Medicine and Health Sciences, Université de Sherbrooke, Longueuil, Québec, Canada

Acknowledgements We would like to acknowledge the Fonds de recherche du Québec-Santé, the Ministère de l'Enseignement supérieur, de la Recherche et de la Science du Québec and the Faculty of Medicine and Health Sciences, Université de Sherbrooke for the financial support. We also thank the personal of Centro Yanapanakusun, the students involved in the Ciclo de estudio 'Pierre Fauchard', carrera profesional de odontología, Universidad San Antonio Abad del Cusco and Professor Fernando Murillo Salazar, director of the Clínica Odontológica 'Alina Rodríguez de Gómez' de la Universidad San Antonio Abad del Cusco, for their help and advice.

Contributors DAB, LRT and IG contributed to the development of the protocol and study design. $D A B$ is responsible for the drafting of this paper, although LRT and IG provided comments on the drafts and have read and approved the final version.

Funding This work was supported by Fonds de recherche du Québec-Santé grant number 31943. Ministère de l'Enseignement supérieur, de la Recherche et de la Science du Québec and the Faculty of Medicine and Health Sciences, Université de Sherbrooke.

Competing interests None declared.

Ethics approval The study protocol and the final documents were approved by the Comité d'éthique de la recherche en santé chez l'humain du Centre hospitalier universitaire de Sherbrooke (Project \#2016-1344).

Provenance and peer review Not commissioned; externally peer reviewed.

Data sharing statement No additional data are available.

Open Access This is an Open Access article distributed in accordance with the Creative Commons Attribution Non Commercial (CC BY-NC 4.0) license, which permits others to distribute, remix, adapt, build upon this work noncommercially, and license their derivative works on different terms, provided the original work is properly cited and the use is non-commercial. See: http:// creativecommons.org/licenses/by-nc/4.0/

\section{REFERENCES}

1. Kandelman D, Arpin S, Baez RJ, et al. Oral health care systems in developing and developed countries. Periodontol 2000 2012;60:98-109.

2. Naidoo S, Myburgh N. Nutrition, oral health and the young child. Matern Child Nutr 2007;3:312-21.

3. Petersen PE, Bourgeois D, Ogawa $\mathrm{H}$, et al. The global burden of oral diseases and risks to oral health. Bull World Health Organ 2005;83:661-9.

4. Kay E, Locker D. A systematic review of the effectiveness of health promotion aimed at improving oral health. Community Dent Health 1998;15:132-44.

5. de La Dure-Molla M, Naulin-Ifi C, Eid-Blanchot C. La carie et ses complications chez l'enfant. EMC Médecine buccale 2012;7:1-11.

6. Petersen PE. Oral health. In: Quah S, Heggenhougen K, eds. International encyclopedia of public health. San Diego, CA: Academic Press, 2008:677-85.

7. Canto MT, Cruz GD. Public Health Issues in Oral Health. In: Finkel ML, ed. Public health in the 21st Century. Santa Barbara, CA: ABC-CLIO, 2011:251-65.

8. Gimenez T, Bispo BA, Souza DP, et al. Does the decline in caries prevalence of Latin American and Caribbean children continue in the new Century? Evidence from systematic review with meta-analysis. PLOS ONE 2016;11:e0164903.

9. Cummins D. Dental caries: a disease which remains a public health concern in the 21 st century. The exploration of a breakthrough technology for caries prevention. J Clin Dent 2010;21:25-37.
10. Pine CM, Adair PM, Petersen PE, et al. Developing explanatory models of health inequalities in childhood dental caries. Community Dent Health 2004;21(Suppl):86-95.

11. Petersen PE. Sociobehavioural risk factors in dental cariesinternational perspectives. Community Dent Oral Epidemiol 2005;33:274-9.

12. Watt RG. Strategies and approaches in oral disease prevention and health promotion. Bull World Health Organ 2005;83:711-8.

13. Moysés SJ. Inequalities in oral health and oral health promotion. Braz Oral Res 2012;26:86-93.

14. García LM, Giraldo SJ, Mossos R, et al. Prevalencia de caries y enfermedad periodontal en escolares del sector público de Cali, 2005. Colomb Med (Cali) 2008;39(Suppl 1):47-50.

15. Locker D, Jokovic A, Stephens M, et al. Family impact of child oral and oro-facial conditions. Community Dent Oral Epidemiol 2002;30:438-48.

16. Sheiham A. Oral health, general health and quality of life. Bull World Health Organ2005;83:644-5.

17. Hosseinpoor A, Itani L, Petersen P. Socio-economic inequality in oral healthcare coverage results from the World Health Survey. J Den Res 2012;91:275-81.

18. Gobernio Regional del Cusco. Plan Regional Concertado de Salud. Cusco, PE: Gobernio Regional del Cusco, 2005.

19. Cooper A, O'Malley L, Elison S, et al. Programmes based in primary schools designed to help prevent tooth decay by changing children's behaviour. Cochrane Database Syst Rev 2013;(5):1-54.

20. Adair PM, Burnside G, Pine CM. Analysis of health behaviour change interventions for preventing dental caries delivered in primary schools. Caries Res 2013;47(Suppl 1):2-12.

21. Albino J, Tiwari T. Preventing childhood caries a review of recent behavioral research. J Den Res 2016;95:35-42.

22. Bourgeois DM, Phantumvanit $\mathrm{P}$, Llodra JC, et al. Rationale for the prevention of oral diseases in primary health care: an international collaborative study in oral health education. Int Dent J 2014;64 (Suppl 2):1-11.

23. Adeleye OA, Ofili AN. Strengthening intersectoral collaboration for primary health care in developing countries: can the health sector play broader roles? J Environ Public Health 2010;2010:272896.

24. Sarker M, Joarder T. Intersectoral collaboration: a novel path to promote community health promotion editorial. Glob Health Prom 2012;194:7-8.

25. Jones DM, Lyle D, Brunero $\mathrm{C}$, et al. Improving health and education outcomes for children in remote communities: a cross-sector and developmental evaluation approach. Gateways 2015;8:1-22.

26. Watt R, Fuller S, Harnett R, et al. Oral health promotion evaluationtime for development. Community Dent Oral Epidemiol 2001;29:161-6.

27. Watt RG. From victim blaming to upstream action: tackling the social determinants of oral health inequalities. Community Dent Oral Epidemiol 2007;35:1-11.

28. Potvin L, Bilodeau A, Gendron S. Trois défis pour l'évaluation en promotion de la santé. Prom Educ 2008;15(1 Suppl):17-21.

29. Kwan SY, Petersen PE, Pine CM, et al. Health-promoting schools: an opportunity for oral health promotion. Bull World Health Organ 2005;83:677-85.

30. Ministerio de Salud. Resolucion Ministerial-Gestion de la Estrategia Sanitaria Nacional de Salud Bucal. In: Lima, PE: El Peruano, 2007:10-20.

31. Presidente de la Republica. Aprueban Plan de Salud Escolar 20132016, con cargo al Presupuesto Institucional del Ministerio de Salud, del Seguro Integral de Salud y de los demas pliegos involucrados. In: Lima, PE: El Peruano, 2013:10-20.

32. Ministerio de Salud. Resolucion Ministerial-Reestructuran la organiszacion y dependencia funcional de las Estrategias Sanitarias Nacional del Ministerio de Salud. In: Lima, PE: El Peruano, 2012;469:100-4.

33. Colegio Ondotologico del Peru. Programa Nacional de Salud Bucal. Lima, PE: Colegio Ondotologico del Peru, 2009.

34. Dirección General de Promoción de la Salud. Módulo de Promoción de la Salud Bucal. Lima, PE: Ministerio de Salud, 2014.

35. Chiang RJ, Meagher W, Slade S. How the whole school, whole community, whole child model works: creating greater alignment, integration, and collaboration between health and education. $J$ Sch Health 2015;85:775-84.

36. Watt RG, Sheiham A. Integrating the common risk factor approach into a social determinants framework. Community Dent Oral Epidemiol 2012;40:289-96.

37. Sheiham A, Alexander D, Cohen L, et al. Global Oral Health Inequalities Task Group-implementation and delivery of oral health strategies. Adv Dent Res 2011;23:259-67. 
38. Pommier J, Ferron C. La promotion de la santé, enfin? L'évolution du champ de l'éducation pour la santé au cours des dix dernières années. Santé Publique 2013;2(2 Suppl):111-18.

39. Bryson JM, Crosby BC, Stone MM. The design and implementation of cross-sector collaborations: propositions from the literature. Publ Adm Rev 2006:44-55.

40. Pesaressi E, Villena RS, van der Sanden WJ, et al. Impact of health centre nurses on the reduction of early childhood caries in Lima, Peru. Br J Med Med Res 2015;5:1169-76.

41. Espinoza-Usaqui EM, de María Pachas-Barrionuevo F. Programas preventivos promocionales de salud bucal en el Perú. Rev Estomatol Herediana 2014;23:101-8.

42. Sánchez-Huamán Y, Sence-Campos R. Efectividad de un programa educativo preventivo para mejorar hábitos de higiene y condición de higiene oral en escolares. Kiru 2012;9:21-33.

43. Goche KR, Alvarado BS. Aplicación de un programa educativo en salud oral en adolescentes de una institución educativa peruana. Rev Estomatol Herediana 2014;22:82-90.

44. Bernabé Ortiz E, Sanchez-Borjas PC, Delgado-Angulo EK. Efectividad de una intervención comunitaria en salud oral: resultados después de 18 meses. Rev Med Herediana 2006;17:170-6.

45. Direccion Regional de Salud Cusco. Plan estrategico institutional 2009-2013. Cusco, PE: Direccion Regional de Salud Cusco, 2009.

46. Petersen PE, Kwan S. Evaluation of community-based oral health promotion and oral disease prevention-WHO recommendations for improved evidence in public health practice. Community Dent Health 2004;21(Suppl):319-29.

47. Porter S, O'Halloran P. The use and limitation of realistic evaluation as a tool for evidence-based practice: a critical realist perspective. Nursing Inq 2012;19:18-28.

48. Pawson R. The science of evaluation: a realist manifesto. London, UK: Sage, 2013.

49. Pawson R, Tilley N. Realistic evaluation. London, UK: Sage, 1997.

50. Ridde V, Robert E, Guichard A, et al. L'approche REALIST à l'épreuve du réel de l'évaluation des programmes. Canadian J Prog Eval 2012;26:37-59.

51. Pawson R, Sridharan $\mathrm{S}$. Theory-driven evaluation of public health programmes. In: Killoran A, Kelly M, eds. Evidence-based public health: Effectiveness and efficiency. Oxford: Oxford University Press, 2010:43-62.

52. Robert É, Ridde V. L'approche réaliste pour l'évaluation de programmes et la revue systématique: De la théorie à la pratique. Mes Eval Educ 2013;36:79-108

53. Dickinson $\mathrm{H}$. The evaluation of health and social care partnerships: an analysis of approaches and synthesis for the future. Health Social Care Community 2006;14:375-83.

54. Porter $\mathrm{S}$. The uncritical realism of realist evaluation. Evaluation 2015;21:65-82.

55. de Souza DE. Elaborating the Context-Mechanism-Outcome configuration $(\mathrm{CMOc})$ in realist evaluation: a critical realist perspective. Evaluation 2013;19:141-54.

56. Hewitt G, Sims S, Harris R. The realist approach to evaluation research: An introduction. Int J Ther Rehabil 2012;19:250-9.

57. Lacouture A, Breton E, Guichard A, et al. The concept of mechanism from a realist approach: a scoping review to facilitate its operationalization in public health program evaluation. Implementation Sci 2015;10:153.

58. Realist Evaluation: an overview. Report from an Expert Seminar with Dr Gill Westhorp, 2011.

59. McEvoy P, Richards D. A critical realist rationale for using a combination of quantitative and qualitative methods. $J$ Res Nurs 2006;11:66-78.

60. Zachariadis M, Scott S, Barrett M. Methodological implications of critical realism for mixed-methods research. Mis Quart 2013;37:855-79.
61. Pawson R, Manzano-Santaella A. A realist diagnostic workshop. Evaluation 2012;18:176-91.

62. Kengne Talla P, Gagnon MP, Dupéré S, et al. Interventions for increasing health promotion practices in dental healthcare settings. Cochrane Database Syst Rev 2014;(2):1-19.

63. Kok G, Gottlieb NH, Commers M, et al. The ecological approach in health promotion programs: a decade later. Am J Health Promot 2008;22:437-42.

64. Astbury B, Leeuw FL. Unpacking black boxes: mechanisms and theory building in evaluation. Am J Eval 2010;31:363-81.

65. Petersen PE, Baez RJ. Oral health surveys basic methods. 5th edn. Geneve, $\mathrm{CH}$ : Organisation mondiale de la santé, 2013.

66. Poutanen R, Lahti S, Hausen H. Oral health-related knowledge, attitudes, and beliefs among 11 to 12-year-old Finnish schoolchildren with different oral health behaviors. Acta Odontol Scand 2005;63:10-16.

67. Bernabé E, Sheiham A, Tsakos G. A comprehensive evaluation of the validity of Child-OIDP: further evidence from Peru. Community Dent Oral Epidemiol 2008;36:317-25.

68. Miles MB, Huberman AM, Saldaña J. Qualitative data analysis: a methods sourcebook. New York, NY: Sage, 2013.

69. Sridharan S, Nakaima A. Ten steps to making evaluation matter. Eval Program Plann 2011;34:135-46.

70. Harris MJ. Evaluating public and community health programs. New York, NY: John Wiley \& Sons, 2010.

71. Mack N, Woodsong C, MacQueen KM, et al. Qualitative Research Methods: A Data Collector's Field Guide. Research Triangle Park, NC: Family Health International, 2005.

72. Tolvanen M, Lahti S, Miettunen J, et al. Relationship between oral health-related knowledge, attitudes and behavior among 1516-year-old adolescents-A structural equation modeling approach. Acta Odontol Scand 2012;70:169-76.

73. Poutanen R. Boys and girls as health-promoting actors-determinants of oral health-related lifestyle among 11-to 12-year-old schoolchildren. University of Oulu, 2007.

74. Vallerand RJ. Vers une méthodologie de validation trans-culturelle de questionnaires psychologiques: Implications pour la recherche en langue française. Can Psychol 1989;30:662-80.

75. Corchuelo J. Sensibilidad y especificidad de un índice de higiene oral de uso comunitario. Colomb Med (Cali) 2011; 42:448-57.

76. Kidd $\mathrm{E}$. The implications of the new paradigm of dental caries. J Dent 2011;39(Suppl 2):S3-8.

77. Gherunpong S, Tsakos G, Sheiham A. Developing and evaluating an oral health-related quality of life index for children; the CHILD-OIDP. Community Dent Health 2004;21:161-9.

78. Manzano A. The craft of interviewing in realist evaluation. Evaluation 2016;22:342-60.

79. Santos HP, Black AM, Sandelowski M. Timing of translation in cross-language qualitative research. Qual Health Res 2015;25:134-44.

80. Maxwell JA. A realist approach for qualitative research. New York, NY: Sage, 2012.

81. Andrew S, Salamonson $Y$, Halcomb EJ. Integrating mixed methods data analysis using NVivo: an example examining attrition and persistence of nursing students. Int J Mult Res Approaches 2008;2:36-43.

82. Baribeau C. Le journal de bord du chercheur. Recherches qualitatives 2005; Hors série(2):98-114.

83. Changkakoti N, Gremion M, Broyon M-A, et al. Terrains de recherche au prisme interculturel de la traduction. Alterstice 2012;2:41-54

84. Sandelowski M. The problem of rigor in qualitative research. Adv Nursing Sci 1986;8:27-37. 